TA'LIMUNA. Vol.7, No. 2, September 2018 P-ISSN 2085-2975

E-ISSN 2622-9889

\title{
MEMAHAMI BALAGHAH DENGAN MUDAH
}

\author{
Muhammad Hafidz \\ Institut Pesantren KH.Abdul Chalim Pacet Mojokerto \\ hafidz@ikhac.ac.id
}

\begin{abstract}
Abstrak
Balaghah merupakan ilmu yang mengkaji keindahan bahasa al-Qur'an. Oleh pelajar bahasa Arab dianggap materi sulit karena beberapa hal, pertama, balaghah membahas mengenai hubungan kata dan ungkapan dengan situasi, lingkungan, dan makna, dalam balaghah ada makna haqiqi (makna denotatif) dan majazi (makna konotatif), ada hubungan ungkapan dengan perasaan, keindahan, dan imajinasi. Kedua, contoh-contoh yang tersaji dalam buku-buku balaghah diambil dari syair-syair arab, yang bahasanya terasa asing bagi pelajar dan cara memahaminya tidak seperti memahami kalimat biasa. Maka perlu ada solusi untuk membantu mempermudahnya, diantaranya adalah perubahan metode pengajaran dan penyusunan buku balaghah dengan pendekatan konstraktif, atau dalam pengertian mudah memahami balaghah dengan kaca mata gaya bahasa Indonesia yang sudah dikenal pelajar sejak awal.
\end{abstract}

Kata Kunci; balaghah, mudah, konstraktif

\section{Pendahuluan}

Balaghah merupakan pelajaran yang paling sulit menurut pelajar bahasa Arab setelah nahwu dan sharaf. Diantara faktor kesulitannya adalah, karena shorof hanya mempelajari pembentukan dan perubahan kata sesuai makna yang dikehendaki, asal kata dan perubahan kelas kata. Begitu juga nahwu, hanya mempelajari hubungan kata dalam kalimat dan kegramatisan ungkapan. Sedangkan balaghah membahas mengenai hubungan kata dan ungkapan dengan situasi, lingkungan, dan makna, dalam balaghah ada makna haqiqi dan majazi, ada hubungan ungkapan dengan perasaan, keindahan, dan 
imajinasi. ${ }^{1}$ Hal-hal tersebut tidak mudah bagi pembelajar memahami dan mempraktekkannya dalam pembelajaran. Selain faktor sifat-sifat kekhasan balaghah tersebut, yang membuat sulit bagi pembelajar juga adalah contohcontoh yang tersaji dalam buku-buku balaghah di kelas diambil dari syairsyair arab. Alih-alih memahami teori balaghah, memahami kosa kata syair saja sulit. Maka perlu ada solusi untuk membantu mempermudahnya.

Ada beberapa penelitian eksperimen dalam kaitannya mempermudah belajar balaghah. Misalkan yang dilakukan oleh Yayan Nur bayan. Dia melakukan analisis konstrastif (al-taqabul al-lughawi), yakni metode sinkronis dalam analisis bahasa untuk menunjukkan persamaan dan perbedaan antara bahasa-bahasa atau dialek-dialek untuk mencari prinsip yang dapat diterapkan dalam masalah praktis, seperti pengajaran bahasa dan penterjemahan. ${ }^{2}$ Dalam analisisnya, ada istilah-istilah balaghah yang sama (walaupun tidak secara penuh) dengan bahasa Indonesia, yang selanjutnya ia buat bahan ajar kuliah. Diantaranya, personofikasi = isti'arah makniyah, alegori = majaz, Alusio = kinayah mausuf $/$ majaz mursal itlaq al-juz, metafora $=$ isti'arah tasrikhiyyah, simile = tashbih, hiperbola $=$ mubalaghah, saj' $^{\prime}$ pararelisme. Dalam hasil penelitiannya, nilai pelajar setelah menggunakan bahan ajar berbasis analisis konstrastif meningkat hingga $7 \% .^{3}$

Selain Yayan Nur Bayan, Husein Aziz, menyusun buku pengajaran IImu al-Balaghah berbahasa Indonesia. Dia menggunakan istilah-istilah gaya bahasa Indonesia untuk memudahkan pemahaman balaghah. Dalam buku tersebut disajikan contoh-contoh dari bahasa Indonesia, hal itu menambah kemudahan mengenal, memahami dan menghafal konsep balaghah yang sedang dibahas. ${ }^{4}$ Al-Qur'an juga mengajarkan kita apabila menerangkan konsep dan makna yang abstrak, maka ia memulai dengan hal-hal yang dikenal penerima pesan, dalam hal ini manusia. Misalnya, dalam surah aD dhuha, Allah menerangkan kebahagiaan dan kesedihan. al Qur an memulai dengan hal atau peristiwa yang orang banyak kenal dan biasa mereka alami dengan wa ad-dhuha (simbol kebahagiaan) wa al-laili idha saja (simbol kesedihan). ${ }^{5}$ Contoh lain, dalam surah al-tariq Allah menerangkan bahwa segala-galanya itu dalam pengawasan Allah. PenyampaianNya dengan hal-hal

${ }^{1}$ Tammam Hasan, al- Ushul-Dirasah Epstimolojiah Li fikr al-'Arabi 'inda al'Arab - Nahw-Fiqh Lughah -al-Balaghah, (Alim al-Kutub), hlm. 273.

${ }^{2}$ Harimurti Kridalaksana, Kamus Linguistik, (Jakarta : Gramedia, 1982), hlm.11

3 Yayan Nur Bayan, Pengembangan Materi Ajar Balaghah Berbasis Pendekatan Konstraftif, Journal Bahasa dan Seni volume 38, 2010.

${ }^{4}$ Husein Aziz, Ilmu al-Balaghah, (Surabaya : UIN Sunan Ampel Surabaya, 2013), hlm. 2

${ }^{5}$ Aishah Abd Rahman Bint Shati', al-Tafsir al-bayani li al-Qur'an al-Karim, (Mesir : dar al-Ma'arif, cet 7, 1926, juz 1), hlm. 36. 
yang manusia kenal, seperti proses penciptaan manusia dari sperma yang menembus kegelapan rahim, dari rahim keluar anak; air hujan yang menembus tanah, dari tanah tumbuh tanaman. Bahasa al-Qur'an memperhatikan manusia dan dunianya. Mengarah ke dalam dan ke luar. Bahasa al Qur an dengan menggunakan huruf dan suara dan diambil dari dunia mereka, manfaatnya adalah memudahkan pemahaman, karena manusia selalu mengukur pengetahuan dengan bahasa dan nalarnya terhadap dunia nyata melalui panca indra, disamping aspek keindahan karena dapat dilihat, didengar dan dirasakan. ${ }^{6}$ Artinya gagasan-gagasan yang disampaikan Allah dalam al-Qur'an menggunakan bahasa yang mendekati bahasa masyarakat yang diajak bicara berikut dunia kehidupannya atau lingkungan masyarakat tersebut. ${ }^{7}$

Dalam pembahasan ini, penulis ingin menerapkan teori-teori hasil penelitian para pakar balaghah dalam membuat kalimat. Karena yang diketahui penulis, buku-buku balaghah yang ada contoh-contohnya dari alQur'an dan syair-syair Arab. Walaupun mengambil contoh dari sumbersumber primer ini penting karena sebagi acuan. Tetapi, contoh-contoh dengan kalimat praktis juga tidak kalah penting agar pelajar bisa membuat kalimat yang tidak kering. Kalimat menjadi indah, efektif dan inderawi serta diperbanyak contoh-contoh untuk memperkuat kaidah.

\section{Pengajaran Balaghah}

1. Kesulitan-Kesulitan Pengajaran Balaghah ${ }^{8}$

Telah disampaikan penulis di pendahuluan, bahwa pembelajaran balaghah merupakan hal yang belum bisa dikatakan mudah bagi pelajar non Arab, ada beberapa kesulitan memahaminya. Ada beberapa faktor yang melatarbelakangi kesulitan-kesulitan tersebut, diantaranya :

a. Karena balaghahnya sendiri (kaidah dan uslubnya).

Uslub dan kaidah balaghah bermacam macam dan banyak perbedaan.

Misalnya Siswa sulit membedakan antara tashbih dan isti'arah dan antara isti'arah tamthiliyyah dan kinayah.

b. Pemahaman Bahasa Arab

${ }^{6}$ Husein Aziz, Bahasa al-Qur'an Perspektif filsafat ilmu, (Pasuruan : Pustaka Sidogiri, 2010), hlm. 16.

${ }^{7}$ Husein Aziz, Bahasa al-Qur'an Perspektif filsafat ilmu , hlm. 79.

${ }^{8}$ Taisir Muhammad, Ziyadat, , Su'ubat ta'lim al-Balaghah al 'Arabiyyah li alnatiqin lighairiha, (Lahor Pakistan: Majallah al qism al-'Araby, Jamiah Punjab, , No 23, 2016), hlm. 221-226. 
Kebanyakan siswa belum memahami pola Bahasa Arab yang sederhana, apalagi memahami bahasa arab dengan susunan yang sulit. Tidak mungkin memahami balaghah, tanpa memahami bahasa Arab

c. Budaya Arab

Belajar bahasa Arab harus juga disertai pengetahuan budayanya. Misalkan kalimat dalam bahasa Arab "fulan kathir al-ramad" (Fulan banyak abunya), maknanya adalah dermawan. Kita tidak bisa memahami kinayah tersebut kalau kita tidak memahami budaya dan kultur arab.

d. Metode Pengajaran

Metode pengajaran balaghah harus mengaitkan dengan kemahiran kemahiran bahasa Arab yang lain, sehingga merupakan satu kesatuan dari Bahasa Arab. Jadi, tidak hanya hafalan kaidah. Selain itu, tidak adanya media pembelajaran merupakan faktor yang menyebabkan kesulitan pengajaran balaghah.

e. Guru

Tidak adanya pengetahuan guru pada tujuan pembelajaran balaghah, tidak ada usaha untuk menggunakan metode yang menyenangkan, guru pengajar bukan pada bidangnya, misalkan : guru alumni timur tengah bidang fiqh dan syariat, pulang ke negaranya mengajar balaghah, serta guru tidak punya spesialisasi (keahlian khusus) Bahasa Arab.

f. Siswa

Kurangnya perhatian siswa pada balaghah, padahal balaghah dibutuhkan pemikiran tajam dan latihan yang ajeg. Faktor lain yang berkaitan dengan siswa adalah karena kurang motivasi.

g. Waktu

Kurangnya waktu untuk pelajaran balaghah dibanding dengan pelajaran lain, biasanya dua jam/minggu.

h. Buku

Guru hanya berpegang pada buku lama, yang penyajian contohcontohnya sulit difahami murid selain arab. Seperti menggunakan syair-syair Arab atau ungkapan-ungkapan yang dikenal hanya oleh orang Arab, buku yang digunakan penuh dengan kaidah-kaidah, perbedaan definisi dan penuh dengan pembahasan klasifikasiklasifikasi tema.

2. Metode Pengajaran balaghah ${ }^{9}$

${ }^{9}$ Su'ad Abdul Karim al-Waaili, Tharaiq tadris al adab wa al-Balaghah wa al ta'bir, baina tandhir wa al tatbiq, (Kairo : Daar al-Syuruq li nasyri wa al tauzi', 2004), hlm. 48-50. 
Secara garis besar, metode pengajaran Balaghah dibagi menjadi dua pandangan : pertama, metode yang memangkas retorika kesatuan balaghah. Metode ini membagi bab balaghah menjadi tiga macam : ma'ani, bayan, badi'. Padahal pembagian ini bertentangan dengan kaidah pendidikan, dari hal mudah ke yang sulit. Maa'ni adalah materi yang paling sulit dalam balaghah. Sehingga pengajarannya kering dari nilai sastra, pemberian contohcontohnya dengan kalimat-kalimat pendek, banyak menekankan pada teori, definisi dan pembagian-pembagian. kedua, Pengajaran balaghah dengan suatu pandangan bahwa balaghah adalah satu kesatuan yang utuh, ia merupakan bahan atau komposisi kalimat yang bernilai sastra. la merupakan bagian yang tidak terpisah dari kajian sastra terhadap teks. Untuk masalah pendefinisian balaghah dan dan masalah tema berasal dari emosional dan perasaan.

Para ahli ada yang membagi menjadi dua metode dalam pengajaran balaghah, yaitu:

a. Tariqah Qiyasiyah (deduktif)

Langkah-langkah metode ini adalah : Guru memberikan kaidah secara langsung, memberikan contoh, kemudian latihan soal. Metode pengajaran ini seperti mengajar nahwu, tujuannya untuk hafal qaidah dan menerapkannya, pemahaman dari hal yang umum ke hal yang khusus. Guru menulis istilah balaghah dan pengertiannya dipapan, diberi contoh-contoh yang ada dibuku ajar yang berkaitan dengan istilah, kemudian menerapkannya.

b. Tariqah Istiqraiyah (induktif)

Guru memberikan contoh-contoh, kemudian beristinbat membuat qaidah dari contoh tersebut, menelaah qaidah balaghah, kemudian diberikan contoh baru.Ini adalah metode terbaik dalam mengajar Balaghah.

\section{Penerapan Pengajaran Balaghah}

Dari metode-metode pengajaran balaghah di atas, kita mengetahui bahwa cara terbaik dalam mengajarnya adalah dengan metode istiqraiyyah dengan pendekatan konstraktif. Dalam pembahasan berikut, penulis memberikan gambaran secara praktis pengajaran tiga tema : tashbi, isti'rah makniyyah dan istiarah tarsikhiyyah.

1. Tashbih/Simile/Gaya Bahasa Perbandingan

a. Contoh Bahasa Indonesia :

1) Kedatanganmu seperti hujan di musim kemarau.

2) Perjalananku ibarat mengarungi samudra.

3) Dunia adalah ladang akhirat.

4) Mereka berdua bagai air di daun talas. 
b. Penjelasan

Kalau kita mengamati contoh-contoh kalimat di atas, ada gaya bahasa membandingkan /mempersamakan sesuatu dengan sesuatu yang lain. Antara keduanya ada titik persamaan. Contoh No (1) Antara kedatangan dan hujan, titik persamaan adalah : keduanya diharapkan. Contoh No (2) Keduanya (Perjalanan hidup dan mengarungi samudra) keduanya sangat panjang. Contoh No (3) titik persamaan dunia dengan ladang adalah keduanya merupakan tempat menanam, menanam pahala/amal di ibaratkan menanam padi. Contoh No (4) Air dan talas merupakan dua benda yang sulit menyatu. Gaya bahasa perbandingan tersebut dalam istilah balaghah disebut TASHBIH.

c. Kaidah

TASYBIH adalah: Ungkapan membandingkan suatu hal dengan hal lain yang mempunyai titik persamaan. Manfaat tasybih : suatu cara untuk mengungkapkan makna atau maksud lebih efektif karena lebih jelas, mengungkapkan makna yang kurang kuat menjadi lebih kuat, yang tidak bisa ditangkap indera menjadi bisa ditangkap indera. Dalam mengungkapkan perbandingan, biasanya menggunakan kata seperti, bagai, umpama atau sejenisnya, tetapi bisa juga tidak menggunakan kata kata tersebut.

d. Contoh-Contoh Tashbih dalam al- Qur'an

al- Qari'ah : 4-5

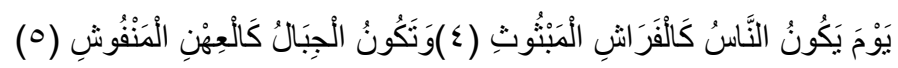

"pada hari itu manusia adalah seperti anai-anai yang

bertebaran,"

"dan gunung-gunung adalah seperti bulu yang dihamburhamburkan."

al-rahman : 14

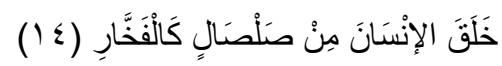

"Dia menciptakan manusia dari tanah kering seperti tembikar." 
al -waqi'ah : 23-24

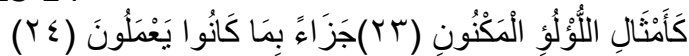

"laksana mutiara yang tersimpan baik"

"sebagai Balasan bagi apa yang telah mereka kerjakan."

e. Penjelasan Contoh al-Qur'an

Perhatikan contoh-contoh dalam al-Qur'an No 1,2,dan 3, terdapat contoh Tashbih. Keadaan manusia di hari Qiyamat diibratkan anai-anai yang bertebaran, gunung-gunung seperti bulu yang berhamburan, penciptaan manusia dari tanah seperti tembikar, dan bidadari diumpamakan mutiara yang tersimpan.

f. Contoh Tashbih dalam Puisi

Untuk lebih menguatkan pemahaman tentang Tashbih, bacalah puisi yang indah dari gus mus berikut ! :

Ibu

Oleh: KH A Mustofa Bisri

Ibu

Kaulah gua teduh

tempatku bertapa bersamamu

Sekian lama

Kaulah kawah

dari mana aku meluncur dengan perkasa

Kaulah bumi

yang tergelar lembut bagiku

melepas lelah dan nestapa

gunung yang menjaga mimpiku

siang dan malam

mata air yang tak brenti mengalir

membasahi dahagaku

telaga tempatku bermain

berenang dan menyelam

Kaulah, ibu, laut dan langit

yang menjaga lurus horisonku

Kaulah, ibu, mentari dan rembulan

yang mengawal perjalananku

mencari jejak sorga

di telapak kakimu 
(Tuhan,

aku bersaksi

ibuku telah melaksanakan amanatMu

menyampaikan kasihsayangMu

maka kasihilah ibuku

seperti Kau mengasihi

kekasih-kekasihMu

Amin).

g. Penjelasan Puisi

Dalam Puisi di atas, Tashbih digunakan dalam menggambarkan "Ibu". Ibu diibaratkan seperti gua teduh, kawah,bumi, gunung, gunung, mata air, telaga, laut, langit, mentari dan rembulan.

h. Penerapan dalam Kalimat

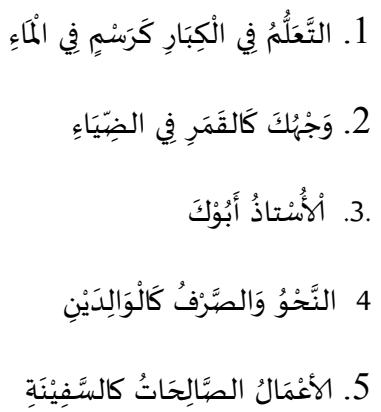

2. Personifikasi (Majaz Isti'arah Makniyah)

a. Contoh Bahasa Indonesia :

1) Angin yang meraung ditengah malam yang gelap menambah lagi ketakutan kami.

2) Aku datang ketika matahari kembali ke peraduannya.

3) Pohon ini bersaksi tentang cinta terakhir kita.

4) Rumput-rumput menari menyambut kedatanganmu.

5) Kesesatan menyelimuti mereka.

6) Kebenaran telah datang.

7) Laut Aceh marah

8) Angin sepoi-sepoi menghiburku

9) Gunung-gunung itu menantang penduduk

10) Bulan malu untuk bersinar malam mini.

b. Penjelasan 
Angin meraung, matahari kembali, rumput menari, kesesatan menyelimuti,kebenaran datang,laut marah,angin menghibur, gunung menantang dan bulan malu. Benda-benda atau makna tersebut seolah-olah bisa berbuat dan beraktifitas seperti manusia. Penggunaan gaya bahasa tersebut disebut Personifikasi. Dalam istilah balaghah bisa disebut Isti'arah Makniyah

c. Kaidah

1) Personifikasi adalah gaya bahasa kiasan yang menggambarkan benda-benda mati atau barang-barang yang tidak bernyawa seolah-olah memiliki sifat-sifat kemanusiaan. Kiasan yang seolah-olah benda mati bertindak, berbuat, dan berbicara seperti manusia.

2) Isti'arah Makniyah memiliki kesamaan dengan Personifikasi dalam gaya bahasa Indonesia. Yaitu seperti halnya tashbih berusaha membangun ungkapan dengan membandingkan suatu hal dengan hal lain yang lebih kuat, hanya saja dalam Isti'arah Makniyah yang dibandingkan dan yang dibandingi tidak disebutkan dalam ungkapan, tetapi diwakili oleh salah satu ciri atau sifatnya. Atau bahasa mudahnya memberi sifat manusia pada benda benda, hewan, dan makna (konsep).

d. Contoh-Contoh Isti'arah Makniyah dalam al- Qur'an Al baqarah: 93

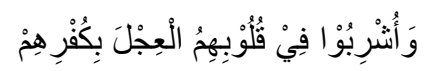

"Dan diresapkanlah(diminumkan) ke dalam hati mereka itu(kecintaan menyembah patung) anak sapi karena kekafiran mereka." Seolah-olah kecintaan menyembah berhala itu seperti minum air yang lezat.

Al-Fajr : 4

$$
\text { وَالََلْيلِ إِذَا يَسْر }
$$

"Dan demi malam apabila berlalu"

Yasin : 38

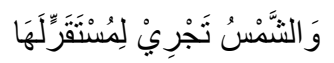


"dan matahari berjalan ditempat peredarannya"

Peminjaman kata "yasr" (berlalu), dalam ayat tersebut, kata "tajri" (berjalan)lebih efektif karena lebih kuat dan lebih hidup karena mempunyai sifat-sifat manusia

At-Takwir: 18

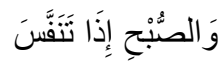

"dan demi subuh ketika bernafas (menyingsing)"

Peminjaman kata "tanaffas" (bernafas) pada subuh menjadikan hidup seperti manusia.

Yunus : 108

قَذْ جَاءَكُمُ الْحَقُ مِنْ رَبِّكُْْ

"Telah datang kepadamu kebenaran(al-Qur'an) dari Tuhanmu"

"al-haq" (kebenaran), "nur", "khauf", datang "ja'a" dengan makna sebenarnya, tetapi datang secara maknawi.

Al Ahzab: 19

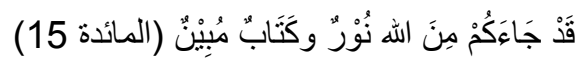

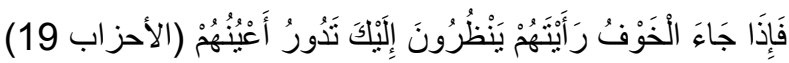

"apabila datang ketakutan (bahaya), kamu Lihat mereka itu memandang kepadamu dengan mata yang terbalik- balik"

Hud : 74

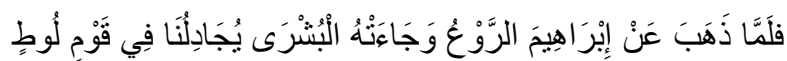

"Maka tatkala rasa takut hilang dari Ibrahim dan berita gembira telah datang kepadanya, diapun bersoal jawab dengan (malaikat-malaikat) Kami tentang kaum Luth." Begitu juga peminjaman kata "dhahaba" (pergi) untuk "al-rou'u".

Qaf : 30

$$
\text { يَوْمَ نَقُولُ لِجَهَنَّمَ هَلِ امْنَلأتَ وَتَقُولُ هَلْ مِنْ مَزِيدٍ }
$$


"(dan ingatlah akan) hari (yang pada hari itu) Kami bertanya kepada Jahannam : "Apakah kamu sudah penuh?" Dia Menjawab : "Masih ada tambahan?" Percakapan Allah dengan jahannam yang sebenarnya tidak bisa bicara merupakan penggambaran kengerian, kekerasan dan panasnya jahannam. Al-A'raf: 154

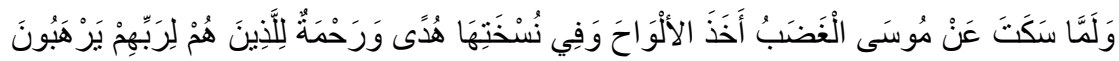

"sesudah amarah Musa menjadi reda, lalu diambilnya (kembali) luh-luh (Taurat) itu; dan dalam tulisannya terdapat petunjuk dan rahmat untuk orang-orang yang takut kepada Tuhannya." Sebenarnya "ghadab" (marah) tidak bisa berbuat seperti manusia "sakata" (diam).

e. Penerapan Isti'arah Makniyah dalam Pembuatan Kalimat

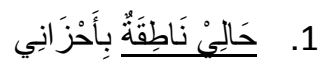

Keaadaanku mengucapkan kesedihanku.

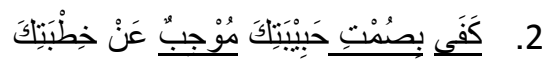

Cukuplah diamnya kekasihmu itu menjawab pinanganmu.

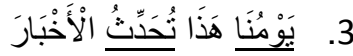

"Hari kita ini menceritakan kabar-kabarnya"

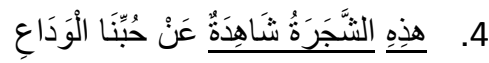

"Pohon ini bersaksi tentang cinta terakhir kita"

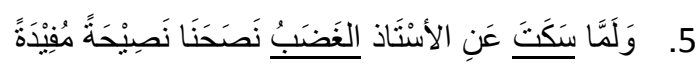

"Dan sesudah amarah ustadz mereda, beliau menasehati kita dengan nasehat yang berguna"

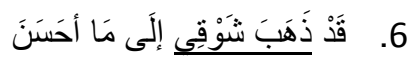

"Rinduku telah pergi kepada hal yang lebih positif"

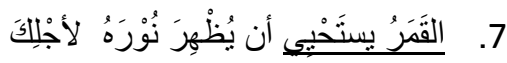

"Bulan malu menampakkan cahayanya karena kamu" 


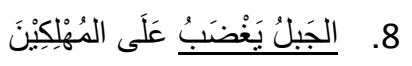

"Gunung marah pada para perusak"

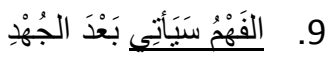

"kefahaman akan datang setelah ketekunan"

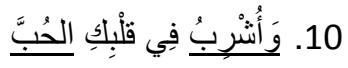

"Aku mengairi/member minum hatimu dengan cinta"

$$
\text { 11. الحَسَدُ يَأكُلُْ الحَِنَاتِ كَمَا يَأَكُلُ النَّارُ الحَطَبَ }
$$

"Hasud memakan kebaikan-kebaikan seperti halnya api memakan kayu"

Peminjaman kata wadi / al audiyah (lembah), bukan turuq atau masalik(jalan) merupakan penggambaran syair-syair yang jauh dari syariat, yang tercipta dari fikiran-fikiran orang kafir dan penuh dengan kesamaran serta ketidak jelasan. Mereka para penyair kafir yang memusuhi dan mendzolimi Nabi diumpamakan seperti orang yang mengembara disuatu lembah. Bisa kita bayangkan, orang yang mengembara tersebut adalah pengemberaan yang membingungkan dan tanpa tujuan yang jelas. Berbeda dengan orang yang melakukan pengembaraan pada suatu jalan, maka ia mempunyai arah yang jelas, visimisinya jelas.

Muhammad : 29

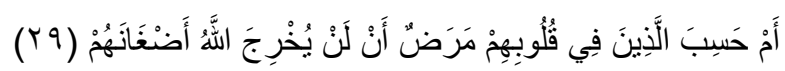

"atau Apakah orang-orang yang ada penyakit dalam hatinya mengira bahwa Allah tidak akan Menampakkan kedengkian mereka?"

Peminjaman kata marad (sakit, makna asal adalah sakit fisik) untuk menggambarkan sakit jiwa (iri, dengki, kemunafikan). Penggunaan kata marad lebih bisa difahami karena inderawi.

3. Metafora (Isti'arah Tasrikhiyah)

a. Contoh Bahasa Indonesia :

1) Bunga desa itu telah pergi. (Gadis cantik).

2) Si jago merah telah dipadamkan ( api). 
3) Dia membawa cindera mata yang bagus (oleh-oleh).

4) Kebanyakan lelaki memang buaya darat (suka berbohong pada wanita).

5) Fatimah adalah buah hatiku satu-satunya (Anak kesayangan).

b. Penjelasan

Kalau kita membaca contoh-contoh di atas, kita dapati katakata yang bergaris bawah mempunyai arti yang tidak hakiki (bukan arti sebenarnya). Bunga desa bermakna gadis cantik, jago merah bermakna api, cindera mata bermakna oleh oleh, buaya darat bermakna lelaki yang suka membohongi wanita dan buah hati bermakna anak kesayangan. Semuanya merupakan analogi yang membandingkan dua hal secara langsung. tetapi dalam bentuk singkat. Istilah tersebut dalam bahasa Indonesia disebut Metafora. Dalam istilah Balaghah disebut dengan Isti'arah Tasrikhiyah.

c. Kaidah

Isti'arah Tasrikhiyah adalah gaya bahasa yang membandingkan suatu hal dengan hal lain yang mempunyai sifat yang sama, sama dengan tashbih, perbedaannya adalah kalau tashbih kedua hal yang dibandingkan (mushabbah) dan yang dibandingi (mushabbah bih) disebutkan. Dalam Isti'arah Tasrikhiyah yang disebutkan hanya yang dibandingi (mushabbah bih).

Metafora sebagai perbandingan langsung tidak mempergunakan kata: seperti, bagai, bagaikan, sehingga pokok pertama langsung dihubungkan dengan pokok kedua.

d. Contoh-Contoh Isti'arah Tasrikhiyah dalam al- Qur'an

Al-Baqarah : 257

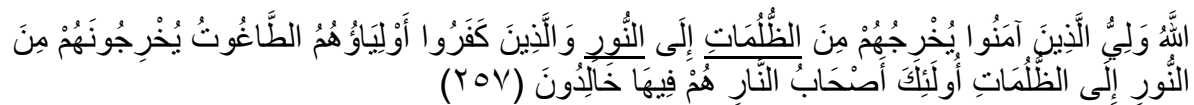

"Allah pelindung orang-orang yang beriman; Dia mengeluarkan mereka dari kegelapan (kekafiran) kepada cahaya (iman). dan orang-orang yang kafir, pelindung-pelindungnya ialah syaitan, yang mengeluarkan mereka daripada cahaya kepada kegelapan (kekafiran). mereka itu adalah penghuni neraka; mereka kekal di dalamnya." 
Peminjaman kata al-zulumat (kegelapan) untuk makna kekafiran atau kesesatan, sedangankan kata al-nur (cahaya) bermakna iman atau hidayah.

Al-Baqarah :256

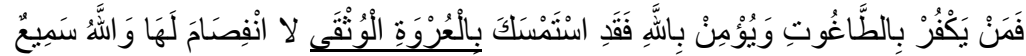
عَليمُ (ro7)

"Karena itu Barangsiapa yang ingkar kepada Thaghut dan beriman kepada Allah, Maka Sesungguhnya ia telah berpegang kepada buhul tali yang Amat kuat yang tidak akan putus. dan Allah Maha mendengar lagi Maha mengetahui."

Peminjaman kata al-'urwah al-wusthqa (buhul tali yang kuat) untuk makna iman yang bersih atau tulus.

Al-Maidah : 100

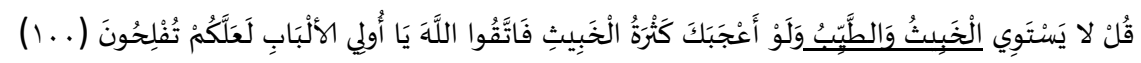

"Tidak sama yang buruk dengan yang baik, meskipun banyaknya yang buruk itu menarik hatimu, Maka bertakwalah kepada Allah Hai orang-orang berakal, agar kamu mendapat keberuntungan." Peminjaman kata khabith untuk makna haram, dan at-tayyib bermakna halal.

Thaha : $27-28$

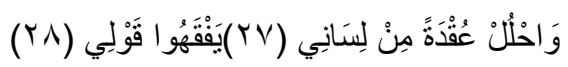

"dan lepaskanlah kekakuan dari lidahku, supaya mereka mengerti perkataanku"

Peminjaman kata wahlul (lepaskanlah) bermakna azil (hilangkanlah), dan "uqdah (simpul, jerat) bermakna aib lisan. "Penghilangan aib" diserupakan seperti melepaskan simpul tali.

Asy-Syu'ara : 224-225

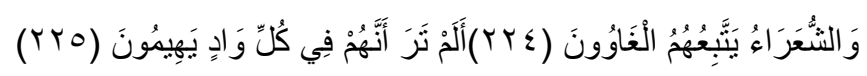


"dan penyair-penyair itu diikuti oleh orang-orang yang sesat. tidakkah kamu melihat bahwasanya mereka mengembara di tiaptiap lembah"

e. Faidah Metafora :

Pemakaian atau peminjaman kata al-zulumat (kegelapan), al-nur (cahaya), al-'urwah\} al-wusthqa (buhul tali yang kuat), khabith, attayyib, 'uqdah (jerat, simpul) bertujuan agar lebih efektif, dan mudah difahami karena bisa ditangkap indera.

f. Penerapan Isti'arah Tasrikhiyah dalam Pembuatan Kalimat

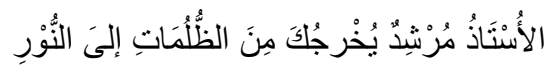

"Ustadz adalah orang yang menunjukkan jalan, ia mengeluarkan kamu dari kegelapan menuju cahaya."

$$
\text { قُلْ لجَمِيْع الطُلابِ أن يُنْعِدُوْا الخَبِيْتَ }
$$

"Katakanlah pada semua murid untuk menjauhi sesuatu yang kotor (menjijikkan)"

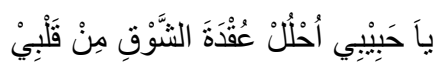

"Wahai kekasihku, lepaskanlah jerat rindu ini dari hatiku."

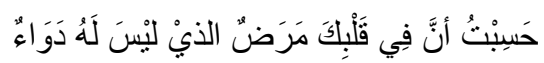

"Saya menyangka dalam hatimu ada sakit yang tidak ada obatnya."

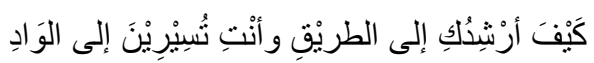

"Bagaimana saya bisa menunjukkan jalan kepadamu, kamu berjalan menuju lembah."

\section{Penutup}

Balaghah merupakan salah satu pelajaran yang sulit bagi pelajar non Arab. Kesulitan tersebut disebabkan oleh beberapa faktor, diantaranya : faktor uslub balaghah, perbedaan budaya, metode pengajaran, faktor guru dan murid, buku ajar, dan waktu yang kurang. Diantara solusi yang bisa menjadi acuan untuk mengatasi kesulitan-kesulitan pengajaran Balaghah adalah : 
1. Memahami balaghah dengan pemahaman bahasa pertama pelajar (memahami Balaghah dengan pemahaman bahasa Indonesia), karena ada kesamaan-kesamaan antara keduanya, walaupun bukan persamaan yang utuh.

2. Untuk memudahkan siswa dalam belajar balaghah, hendaknya dengan diajarkan juga persamaannya dalam Bahasa Indonesia. Misalnya : Tashbih $=$ simile, personifikasi $=$ isti'arah makniyah, dan metafora $=$ isti'arah tarsikhiyyah.

3. Mengajar balaghah dengan metode Istiqra'i dan menggunakan buku yang tidak hanya memperbanyak teori dan klasifikasi-klasifikasi merupakan metode terbaik.

4. Langkah metode Istiqra'i adalah : guru memberikan contoh-contoh yang mengandung unsur balaghah, membuat konsep definisi istilah balaghah, memberikan contoh baru, dan latihan soal.

\section{Daftar Rujukan}

Abdul Karim al-Waaili, Su'ad, Tharaiq tadris al adab wa al- Balaghah wa al ta'bir, baina tanzir wa al tatbiq, Kairo : Dar al-Shuruq li nashr wa al tauzi', 2004.

Al -Sabuni, Muhammad Ali, Safwah al-tafasir, Indonesia: Daar al kutub alIslamiyah, cet ke-1, 1999.

Aziz, Husein, Ilmu al-Balaghah, Surabaya : UIN Sunan Ampel Surabaya 2013.

Aziz, Husein, Bahasa al-Qur'an Perspektif filsafat ilmu, Pasuruan : Pustaka Sidogiri, 2010.

Abd Rahman Bint Shati', 'Aishah, al-Tafsir al-bayani li al-Qur'an al-Karim, Mesir: dar al-Ma'arif, cet 7, 1926.

Bisri, A. Mustofa, Aku manusia, Rembang : CV. MataAir Indonesia, 2016.

Hasan, Tammam, al- Ushul-Dirasah Epstimolojiah Li fikr al-'Arabi 'inda al'Arab - Nahw-Fiqh Lughah -al-Balaghah, Beirut : Alim al-Kutub, tt.

Husain, Abdul Qadir, al-Qur'an wa al-Surah al-Bayaniyah, Beirut: Alim alKutub, cet ke-8, 1985.

Kridalaksana, Harimurti, Kamus Linguistik, Jakarta : PT. Gramedia, 1982.

Keraf, Gorys, Diksi dan Gaya Bahasa, Jakarta: Gramedia Pustaka Utama, cet. XX, 2010.

Nur Bayan, Yayan, "Pengembangan Materi Ajar Balaghah Berbasis Pendekatan Konstraftif", Journal Bahasa dan Seni vol. 38, 2010. 
Warson, Ahmad Munawwir, Al Munawwir , Yogyakarta : Pustaka Progressif, Cetakan ke-14, 1997.

Ziyadat, Taisir Muhammad, "Su'ubat ta'lim al-Balaghah al 'Arabiyyah li alnatiqin li ghairiha," Majallah al qism al-'Araby, Jamiah Punjab, Lahor Pakistan, No 23, 2016. 